\title{
Dilemas e conflitos de ser mãe na vigência do HIV/Aids*
}

\author{
Dilemmas and conflitcs of being a mother with HIV/Aids \\ Dilemas y conflictos de ser madre en casos de $\mathrm{VIH} / \mathrm{Sida}$
}

Marli Teresinha Gimeniz Galvão', Gilmara Holanda da Cunha', Márcia Maria Tavares Machado'

'Universidade Federal do Ceará. Departamento de Enfermagem. Curso de Pós-graduação em Enfermagem. Fortaleza, CE

Submissão: 16/03/2009

Aprovação: 17/09/2009

\section{RESUMO}

Objetivou-se apreender os dilemas e conflitos revelados por mulheres Que engravidaram na vigência da infecção pelo HIV/Aids. Estudo Qualitativo com oito mulheres atendidas em ambulatório em Fortaleza-CE. Mediante entrevistas observou-se Que as mulheres gestam com expectativa do resultado da sorologia do concepto; depois de nascidos vivenciam incertezas e mantêm superproteção da criança. Relatam maneiras inadequadas da comunicação do diagnóstico e pouca orientação para gestar em face do HIV. As mulheres transformam o desejo de ser mãe em realidade. Para elas, lidar com uma criança com possibilidade de contrair infecção pelo HIV é algo além de sua capacidade. Conclui-se ser essencial oferecer suporte emocional e social para essas mulheres independente das fases da vida.

Descritores: HIV; Saúde da mulher; Soropositividade para HIV; Gravidez.

\section{ABSTRACT}

This study aimed to apprehend the dilemmas and conflicts revealed by women infected with HIV/Aids who got pregnant. This Qualitative study involved eight women attended at an outpatient clinic in Fortaleza-CE. Through interviews, it was observed that the women go through their pregnancy with expectations about their child's serological status; after birth, they live with uncertainties and overprotect the child. They report on inadequate ways of communicating the diagnosis and lack of advice about pregnancy in cases of HIV. These women transform the desire of motherhood into reality. According to them, dealing with a child with the possibility of catching HIV goes beyond their capacity. In conclusion, it is essential to offer emotional and social support to these women, independently of the phase in life they are in.

Key words: HIV; Women's health; HIV Seropositivity; Pregnancy.

\section{RESUMEN}

La finalidad fue aprehender los dilemas y conflictos revelados por mujeres infectadas por el VIH/Sida Que Quedaron embarazadas. Estudio cualitativo con ocho mujeres atendidas en ambulatorio en Fortaleza-CE. Mediante entrevistas fue observado Que las mujeres gestan con expectativa del resultado de la serología del concepto; después de nacidos viven incertidumbres y mantienen protección exagerada del niño. Relatan maneras inadecuadas de comunicar el diagnóstico y poca orientación para gestar ante el VIH. Las mujeres transforman el deseo de ser madre en realidad. Para ellas, lidiar con un niño con posibilidad de contraer infección por el VIH es algo más allá de su capacidad. Se concluye Que es esencial ofrecer soporte emocional y social para esas mujeres independientemente de las fases de la vida.

Descriptores: VIH; Salud de la mujer; Seropositividad para VIH; Embarazo.

* Parte da pesquisa "Práticas alimentares de crianças de zero a dois anos filhos de mães soropositivas para o HIV", financiada pelo CT-Saúde/MCT/CNPQ/MS, Processo 505267/04-7.

AUTOR CORRESPONDENTE Marli Teresinha Gimeniz Galvão. Rua Alexandre Baraúna, I I I 5, Bairro Rodolfo Teófilo. CEP 60430- I60, Fortaleza, CE. E-mail: gilmaraholandaufc@yahoo.com.br 


\section{INTRODUÇÃO}

A pandemia da Aids tem se convertido numa catástrofe humana, social e econômica com conseQüências de largo alcance para os indivíduos em todos os países ${ }^{(1)}$. Embora o Brasil apresente um dos programas mais estruturados de combate ao HIV (Vírus da Imunodeficiência Humana), tem enfrentado grandes desafios na terceira década da epidemia, especialmente a feminização e como conseQüências o aumento da transmissão vertical (TV), aspecto observado em todo o país, com a notificação de crianças nascidas expostas ao risco de aQuisição do HIV.

Independente do status sorológico, as mulheres desejam um filho, sobretudo por considerá-lo como a possibilidade da extensão da própria vida e confiantes na terapêutica profilática. Este fato representa um alento e uma esperança de vida, além da realização como mulher. Na oportunidade de ser mãe, as soropositivas ao HIV também encontram um estímulo para cuidar ainda mais da própria saúde, sentem-se mais fortes e capazes de resistirem à doença. Dessa forma, a existência de um filho constitui uma espécie de desafio contra a doença: enquanto o fato de ser mãe representa a morte, as crianças representam a vida ${ }^{(2-3)}$.

Alguns fatores maternos estão associados ao aumento do risco de transmissão do HIV para o filho, como os relacionados ao estado clínico e imunológico, os virais, os comportamentais e os obstétricos. É necessário o monitoramente de todos esses fatores durante o curso gravídico associado ao uso de anti-retroviral. Tais circunstâncias vivenciadas se somam, e, assim, em virtude do HIV, tornam a gravidez um período de apreensão e expectativas.

A maternidade ultrapassa a gravidez, pois é um processo sujeito às sucessivas mudanças e tarefas de adaptação no desenvolvimento $^{(4)}$. Circunscrita nesse contexto, a mulher soro-positiva para o HIV pode sofrer diversas situações permeadas por preconceito, estigma, sofrimento tanto individual como familiar $^{(5-6)}$ e medo Quanto ao futuro da criança $^{(3)}$. Também há receio da revelação do diagnóstico, barreiras para trabalhar e escassez de redes sociais encorajadoras para a maternidade ${ }^{(2,6)}$. Todas essas Questões exigem maior atenção, uma vez Que a mulher precisa ser orientada sobre seus direitos reprodutivos e melhor ocasião para conceber. Precisa também receber informações sobre cuidados para o pré-natal, parto e puerpério. Diante disso, enfatiza-se a importância do acompanhamento da portadora do HIV em idade reprodutiva.

Ante ao exposto e em decorrência da experiência assistencial prestada a esse grupo de mulheres, surgiu uma ineuietação, a saber: Mulheres soropositivas ao HIV vivenciam situações embaraçosas e conflituosas durante a gravidez e pós-parto?

Em virtude desta inquietação associada à possibilidade de contribuir com informações para os serviços de saúde sobre como vêm sendo orientadas às mulheres em fase reprodutiva na vigência do HIV, objetivou-se neste estudo apreender os dilemas e conflitos revelados por mulheres Que gestaram na vigência da infecção pelo HIV/Aids.

\section{MÉTODO}

Estudo Qualitativo, caracterizado por propiciar uma compreensão ampla e mais profunda a respeito dos comportamentos humanos complexos, além de gerar elementos ricos e descritivos, Que promovem sensibilidade aumentada às experiências dos outros, ampliando a compreensão e fornecendo uma base para intervenção possível de melhorar a Qualidade de vida ${ }^{(7)}$. Teve-se como cenário o ambulatório do Hospital São José de Doenças Infecciosas, referência para HIV/Aids do Estado do Ceará, localizado na cidade de Fortaleza, no período de março a junho de 2005.

Integraram-se o estudo oito mulheres com diagnóstico de infecção pelo HIV/Aids, cujo critério para escolha foi ter filho menor de um ano, concebido depois do diagnóstico da infecção pelo HIV, e aceitar participar do estudo. O número de participantes foi determinado pela saturação das informações, ou seja, a repetição dos dados, além de responder às inquietações e ao objetivo da investigação.

Para obtenção de dados utilizou-se um roteiro semi-estruturado com vistas a nortear as entrevistas, as Quais foram gravadas em ambiente privado, sem a interferência externa e em horários de pouco fluxo no ambulatório. As entrevistas duraram de 30 a 45 minutos. O roteiro contemplava perguntas de caráter subjetivo destinadas a apreender situações vivenciadas durante a gravidez e pós-parto e explorar as situações embaraçosas e conflituosas vivenciadas durante estes períodos. Ao final de cada entrevista, foi dada oportunidade para Que cada mulher pudesse tecer comentários adicionais sobre o assunto.

Após a captação dos discursos ou falas, procedeu-se à análise. Inicialmente, houve o processo de transformação do relatado em um texto escrito. Os depoimentos foram explorados ouvindo-se e lendo-se exaustivamente cada um individualmente. Para o tratamento das informações obtidas, adotou-se a análise de conteúdo ${ }^{(8)}$, composta de três fases: 1 . Organização e sistematização das idéias; 2. Exploração do material, correspondente à transformação sistemática dos dados brutos do texto, por recorte, agregação e enumeração, visando atingir uma representação do conteúdo ou da sua expressão e, conseQüentemente, a compreensão do texto; e 3. Tratamento dos resultados, a inferência e a interpretação. Foram analisados os depoimentos e categorizados por inferência de conteúdos semelhantes, formulando-se as seguintes categorias: Apreensões em face a descoberta do HIV; O desejo da maternidade; Superproteção do concepto; Privação do aleitamento materno; Maternidade envolvida de preconceito.

Conforme o exigido, o estudo foi aprovado pelo Comitê de Ética em Pesquisa do Hospital, sob o protocolo no 38/2005. Para garantia do anonimato das participantes, optou-se por denominá-las pela letra " $\mathrm{M}$ " seguida do número da entrevista ( 1 a 8 ).

\section{RESULTADOS E DISCUSSÃO}

Nessa secção, contextualizam-se os aspectos socioeconômicos das mulheres infectadas pelo HIV Que foram mães após o diagnóstico da infecção. Desta forma se favorece o entendimento das diferentes situações encontradas no estudo.

Enquanto as mulheres tinham entre 21 e 45 anos de idade, seus filhos tinham menos de 12 meses. Todas informaram a contaminação por relações sexuais. Entre elas três mulheres vivenciaram duas vezes uma gestação após o diagnóstico de HIV. Duas delas haviam descoberto o diagnóstico durante o primeiro pré-natal e uma relatou conhecimento do diagnóstico anterior às gestações. No concernente ao tempo de intervalo médio entre uma gravidez e outra, era de dois anos. Cinco conheceram o diagnóstico 
da infecção em decorrência da doença do parceiro.

Em relação à situação conjugal, cinco mulheres conviviam com o companheiro, duas eram solteiras e uma era viúva (o parceiro havia falecido em decorrência da aids durante a gestação). Quanto à escolaridade, cinco mulheres informaram ensino fundamental incompleto. Sobre a renda per capita, 75\% delas declararam valores entre cinqüenta e cem reais ( $R \$ 50,00$ e $R \$ 100,00)$. Na época, o valor do salário mínimo era de $\mathrm{R} \$ 300,00$ (trezentos reais).

A seguir, descrevem-se as categorias apreendidas a partir das falas das mulheres entrevistadas.

\section{Apreensões em face da maternidade}

$\mathrm{Na}$ maioria das mulheres HIV+ a gravidez é uma escolha desejada. Muitas vezes, entretanto, esta decisão é vista de forma negativa por parte dos profissionais de saúde ${ }^{(9)}$. Tal atitude é inaceitável, pois estes profissionais deveriam combater o preconceito. No período gestacional, as gestantes com infecção pelo HIV requerem um acompanhamento especial, particularmente por estarem passando uma fase singular da vida, necessitam de uma forma de abordagem peculiar: o aconselhamento ${ }^{(10-1)}$.

Ao seu modo, nesta condição, cada gestante vive uma experiência específica. Uma das participantes, mãe de dois filhos, descobriu ser soropositiva para o HIV na primeira gestação, ainda na sala de parto, conforme pode ser observado pelo depoimento:

[... descobri ... Quando eu estava na sala de parto e a "doutora" disse: "eu vou fazer um cortezinho no seu dedo, mas não vai doer nada, eu posso?" Pode. Na seqüência [destaque dos autores] ... ela me disse: vou lhe dizer uma coisa, você tem Aids... Estava cheio de doutores dentro da sala... aí eu fieuei assim [referindo-se a sentimento de vergonha associado a tristeza] ... aí uma doutora bem arrumada disse para aquela Que havia me dado a notícia: "não era pra ter dito não" [referindose à forma e ao local]. (M4)

No Brasil, recomenda se oferecer o teste anti-HIV para todas as gestantes, mediante seu consentimento, com aconselhamento pré e pós-teste, independente de apresentar situação de risco para a infecção pelo HIV ${ }^{(12)}$. Quando, por QualQuer razão, o teste antiHIV não for realizado durante o período pré-natal, este deve ser feito no momento da admissão na maternidade, com a utilização de estratégias de aconselhamento e testagem específicos para essa condição. Mas, o uso do teste rápido na maternidade não exclui a necessidade de aconselhamento pré e pós-teste, devendo-se preservar o sigilo e o consentimento informado ${ }^{(11)}$.

Determinadas situações são inadeQuadas em serviços de saúde, tal como observado neste estudo, no caso, a revolta de uma participante, principalmente no referente ao sigilo do diagnóstico, como mostra a fala:

[... eu não estava bêbada e nem drogada Quando eu disse para a profissional [ainda na sala do parto] Que não era pra ela dizer pra ninguém que eu estava contaminada... ela saiu da sala... e disse para o meu marido que eu tinha HIV... ele ficou desesperado, louco, pensava que eu ia morrer ali mesmo no hospital. (M4)

Todo ser humano tem à preservação de seus direitos. Portanto, as mulheres grávidas, soropositivas ou não, essa condição deve ser garantida. Situações inadeQuadas não devem permear a assistência nos serviços. Especialmente dentro dos serviços de referência as mulheres reQuererem atenção significante como o consentimento informado, para a realização do teste, confidência do resultado, indicação e acesso para serviços especializados. Essas determinações visam reduzir o estigma e a discriminação.

Determinados aspectos agravam ainda mais a reação da mulher diante da contaminação pelo HIV. Por exemplo: em mulheres com parceiro único este tipo de contaminação traz medo da morte, associado à raiva, por se sentir traída, assim como receio do preconceito da sociedade:

[...] ah! pra mim parece que o mundo tinha acabado porque eu nunca pensei Que ele fosse fazer isso comigo [referindo-se a transmissão], porque foi meu primeiro namorado, meu primeiro homem e meu único marido. Por isso não se deve confiar em ninguém... Eu o deixei porQue não tinha nem condições de ficar com ele, depois que ele fez isso comigo. [... fiquei tão traumatizada que pra mim todos os homens são iguais. Prefiro ficar sozinha com as minhas filhas. (M2)

Como mostra o dia-a-dia, a Aids parece interferir no campo das relações humanas, em especial nas amorosas, onde a fidelidade é muito valorizada. Sobressai um código culturalmente instituído, por meio do Qual se atribui à mulher o papel de esposa fiel, enquanto a infidelidade do homem já é algo esperado e aceito ${ }^{(13)}$.

[... . na hora do resultado eu senti assim aquela vontade de não viver mais, porQue eu fiquei com vergonha dos meus outros filhos Que já estavam grandes, do meu pai, da minha família. (M5)

Diante da vergonha do diagnóstico muitos ocultam a infecção. Segundo indica determinado estudo, freqüentemente a revelação do diagnóstico traumatiza, causa sensação de medo do abandono e discriminação pelos familiares, companheiros e amigos.

Assim, o portador do HIV/Aids aparece como dotado de comportamento ou de atitudes impróprias ao bem-estar social. Contudo a falta de esclarecimento é responsável por situações conflituosas vividas pelas pessoas portadoras de algum tipo de doença sexualmente transmissível, principalmente aquelas infectadas ${ }^{(14)}$.

Para uma mulher soropositiva para o HIV a gravidez pode constituir um "relembrar" da sua condição, confirmando constantemente o receio de receber um filho doente, ou de haver complicações no decorrer da gravidez:

[...] é triste né, porque essas duas gravidezes foram as mais cheias de problema, ter Que acompanhar o pré-natal, dar o remédio... (MI)

[...] eu falei Que eu Queria abortar e que eu tinha medo de ter [o filhol porque o pessoal dizia que morria na hora do parto, aí o doutor disse que o melhor era ter o nenê. (M6)

Inevitavelmente, o significado da soropositividade desencadeia angústias ampliadas ainda mais Quando a gestação se dá sob o 
signo da aids. Tal realidade remete o imaginário social à dor, à doença e, sobretudo, à morte, pelos riscos prementes de gerar um filho. Em algum momento, adoecer e até morrer faz com Que a mãe se mostre, muitas vezes, perplexa e confusa em relação à saúde do recém-nascido ${ }^{(15)}$.

\section{O desejo da maternidade}

Algumas mulheres soropositivas para o HIV consideram Que gestar uma criança é condição indispensável à sua própria vida. Segundo se verifica, mesmo Quando orientadas, as mulheres transformam seu desejo de ser mãe em realidade:

[...] a gente tem a orientação e mesmo assim eu arrisquei ter um filho porque toda mulher Quer ter um filho e graças a Deus eu tive duas crianças maravilhosas e são soronegativos, mas é muito difícil enfrentar tudo isso... (M7)

De modo geral, a maternidade é reforçada pelo papel social Que representa, até mesmo pela inserção feminina na sociedade, pela cultura e pela moral. Aspirar ter filhos é um desejo inato, para dar sentido à vida, por causa das normas em Que foram socializados, ou pela construção da sua identidade feminina ou viril. Embora exista o desejo da concepção, a condição sorológica, muitas vezes, torna-se uma barreira para a sua realização ${ }^{(19)}$.

O sonho de ser mãe é evidenciado independente do status sorológico de HIV e do número de filhos, antes ou após o diagnóstico da infecção. Aproximadamente $40 \%$ das mulheres HIV positivas do Nordeste do Brasil expressam desejo de ter filhos, independente da fase da doença ${ }^{(20)}$. De acordo com estudo avaliado desse sentimento, muitas mulheres tiveram esse desejo inter-rompido, pois a doença foi a razão para esterilização (laqueadura tubária) após o parto em mais da metade daquelas com diagnóstico do HIV. Nesse caso, a recomendação profissional foi um fator decisivo para essa situação(21). Entretanto, mulheres infectadas pelo HIV devem ter seus direitos reprodutivos respeitados. Ademais, simbolicamente, para essa mulher, ter filho significa uma forma de dar continuidade a uma vida, já marcada por uma morte prematuramente anunciada.

\section{Superproteção do concepto}

O cotidiano da mãe portadora do HIV/Aids é dominado por interrogações. Ela convive com a expectativa se o filho será ou não portador do HIV, se ela sobreviverá o suficiente para cuidar do filho ou se este ficará sob os cuidados da família. Todos os membros da família vivem intensamente esta expectativa, sem saber o futuro da mãe e do filho, conforme descrevem:

[...] a única coisa Que eu imagino são as minhas filhas... se um dia eu faltar [morrer] para elas... Eu sei Que minha família vai cuidar, mas não é a mesma coisa, a gente Que é mãe tem um carinho a mais. Já não tem pai e ... ficar sem mãe eu acho cruel. (M8)

[...] cuidar da minha filha... é tipo assim como se ela fosse especial e ter sempre cuidado. A minha primeira filha não teve nada [comparando o cuidado com outra filha]. A gente tem carinho por todas duas, mas essa é especial por causa dos problemas dela. (M2)

Pelos relatos, como se percebe, as mães portadoras de HIV/
Aids desenvolvem sentimentos como culpa, angústia e superproteção em relação ao filho. Dispensa-lhe mais cuidados, como forma de compensação.

\section{Privação do aleitamento materno}

O aleitamento materno representa risco adicional de $14 \%$ a $22 \%$ de contágio pelo HIV. Por esse motivo, contra-indica a amamentação direta ao seio materno, pois, desse modo, espera-se diminuir a probabilidade de contaminação da criança durante a gravidez e no pós-parto, Quando a mulher deve ser orientada a inibir a lactação e receber instruções sobre como usar a fórmula infantil, de modo Que minimize os riscos de contaminação e erros durante a preparação do leite artificial $^{(11,16)}$.

No entanto, como se pode observar, ainda há falta de orientação Quanto à não amamentação e cuidados com a mama. É preciso orientá-la, pois caso a mulher não receba medicamento inibidor da lactação e não tenha as mamas enfaixadas, poderá se sentir incomodada e com desconforto ${ }^{(17-18)}$. Conforme expõem as falas, as mães, por não receberem essas orientações, relatam situações de dor nas mamas:

[...] foi horrível porque eu tinha muito leite e não explicaram essa parte de amamentação... eu pensava que a única coisa Que eu não poderia era ter o filho normal e Que tinha Que ser cesárea, mas não sabia Que não podia amamentar não. (M3)

Estes momentos constrangedores, particularmente poreue o ato de não amamentar desperta sentimentos de impotência na mãe:

[...] eu me sentia tão assim... (impotente), uns dizia Que ela não ia se criar visto Que não mamava. Meu peito doía, aí, antes de sair do hospital, eu tomei uma injeção pra secar o leite. (M6)

\section{Maternidade envolvida de preconceito}

A maternidade, cujo papel social em nossa cultura parece ser esperado e valorizado, comumente desejado pelas mulheres, pode se tornar ameaçada pela condição sorológica ${ }^{(22)}$. Esta ameaça pode estar presente até nos serviços de saúde. Muitas vezes a mulher Que vive com HIV/Aids encontra acolhimento insatisfatório pela equipe de saúde. É comum o relato da pouca atenção dos serviços para as relações dialógicas favoráveis e o acolhimento prestado nesse momento delicado na vida dessas mulheres. Estudo demonstrou despreparo dos profissionais para assistir estas clientes, Quer por falta de conhecimento, habilidade técnica na área, ou referente à Questão ética Que envolve esta assistência ${ }^{(23)}$.

Neste contexto, situação semelhante foi relatada pelas participantes da presente pesquisa, como se ilustra:

[... no parto... eu fiquei numa sala isolada sem nenhuma pessoa chegar perto, nem a enfermeira não ia limpar lá porQue era cheio de sangue [...] e se chegasse alguém elas diziam assim: "hei vem pra cá, não pode ir pra aí não". Isso tudo elas faziam na minha frente...(M4)

Situações como esta resultam da desinformação, do preconceito moral e ético. Revela falta de humanização dos profissionais em serviços de referência em saúde destinados a essa população, bem 
como escassez de orientações acerca do manejo adequado para pacientes soropositivos. Tais fatos geram constrangimento por parte dos usuários do serviço. No dia-a-dia essas Questões permeiam a vida dos pacientes e se estende ao âmbito familiar e à sociedade como um todo, conforme exposto:

[...] teve uma irmã minha Que Quando ela soube Que eu estava [soropositival ela ficou com nojo e medo. Ela não se sentava no canto que eu me sentava [...] Eu tomava água no copo e a seguir ela escaldava ou sacudia e não Queria mais aquele copo. (M5)

Conviver com um dos integrantes da família acometido pelo HIV é conviver movimentando-se para além das fronteiras físicas Que a doença apresenta, indo em direção a um mundo carregado de representações contextualizadas e criadas a partir de interpretações da situação vivenciada. Cada família vivencia esse processo de acordo com sua cultura e comportamento ${ }^{(14)}$.

[...] as pessoas vêem isso [referindo-se à doença] como um "bicho de sete cabeças" e eu prefiro não falar essa situação para ninguém... nem para a família. (M8)

Diante da soropositividade, surgem sentimentos contraditórios, nojo, medo, culpa. O receio de desvelar o diagnóstico reside no temor Quanto ao julgamento social, ou seja, há o medo da humilhação, da vergonha e da culpa, porQuanto, ainda hoje, a aids é sinônimo de exclusão social. O indivíduo com esta doença é estigmatizado pela sociedade, Quer seja em países em desenvolvimento ou naqueles desenvolvido. Dessa forma, o segredo passa a ser uma forma de sobrevivência do grupo, pois o adoecer de aids é uma situação também vivida pelos familiares ${ }^{(2,14)}$.

\section{CONSIDERAÇÕES FINAIS}

Os achados do presente estudo, de caráter exploratório, apontam para a relevância da realização de pesquisas na área temática Que compreendem o HIV/Aids e o universo de mulheres infectadas, favorecendo a compreensão dos conflitos existentes entre as mulheres-mães. Ademais, a opção pelo uso de metodologia Qualitativa, mediante entrevista face a face, esclareceu a pergunta e foi condizente com os objetivos propostos.

Pelo observado, as mulheres infectadas pelo HIV mantêm expectativas durante a gravidez e após o nascimento dos filhos. Isso independente de ter sido sua primeira gestação. No cotidiano dessas mulheres, a possibilidade da contaminação do concepto e a expectativa do exame são dilemas dominantes. Dúvidas, incertezas, geram ansiedade e desencadeiam nessas mulheres-mães a superproteção da criança nascida sob exposição do HIV.

Mais uma vez adverte-se. Tal situação exige cuidados específicos. Até mesmo a maneira e o local inapropriados de comunicar o resultado da sorologia anti-HIV. Para essas mulheres repercutem na sua vida e no âmbito familiar. Como observado ainda é visível a falta de sensibilidade e de ética profissional nos serviços de saúde.

Outro fato observado foi o escasso conhecimento das mulheres sobre o momento ideal para conceber e os cuidados necessários para o controle da infecção pelo HIV no pré-natal, parto e puerpério. Estas são Questões pouco reforçadas ou não esclarecidas durante os seguimentos de saúde. Nesse contexto, o aconselhamento pré e pós-teste tem grande importância para conscientizar essas mulheres acerca dos cuidados com a saúde. Tais momentos são indispensáveis com vistas a orientá-las para viver o processo de maternidade devidamente esclarecido, uma vez Que este terá peculiaridades dependentes de cuidados diferenciados para os Quais se exigem serviços e profissionais de saúde especializados. É imperativo orientar essa mãe acerca de situações passíveis de ocorrer com seu filho, pois elas são as maiores provedoras de cuidados dos filhos.

Em relação ao diagnóstico, deve ser mantido sigilo, sobretudo porque muitos pacientes sofrem pelo medo do estigma decorrente da doença e do preconceito, principalmente Quando pensam no futuro do filho. Para as mães, lidar com uma criança em possibilidade de contrair infecção pelo HIV ou de ser portadora, é algo além da sua capacidade. Portanto é essencial oferecer suporte emocional e social para toda a família Que convive com o HIV/Aids.

Pode-se enfim, compreender o seguinte: as mulheres, especialmente aquelas Que estiveram grávidas na vigência do HIV, se mantêm apreensivas durante o processo de maternagem. Urge, então, propiciar-lhes suporte emocional e social independente das fases da vida. Associado a isso é preciso manter constantes discussões com profissionais de saúde sobre a abordagem e o cuidado humanizado direcionados ás mulheres, particularmente as gestantes, pois a gestação, o parto e o pós-parto são períodos singulares na vida da mulher. Nestas ocasiões ocorrem muitos conflitos pessoais os Quais geram maior nível de ansiedade e medo determinados pela possibilidade da transmissão do HIV para o filho.

Minimizar essa ansiedade e esses medos mediante cuidadosos esclarecimentos é também atribuição do profissional de saúde. Assim, de forma humanizada, cabe-lhes contribuir para amenizar os dilemas e conflitos de ser mãe na vigência do HIV/Aids.

\section{REFERÊNCIAS}

1. Organização Mundial de la Salud. Estrategia mundial del sector sanitario para el VIH/ SIDA, 2003-2007: um marco para las alianzas y la acción. Ginebra: OMS; 2003.

2. Cechim PL, Selli L. Mulheres com HIV/AIDS: fragmentos de sua face oculta. Rev Bras Enferm 2007; 60(2): 145-9.

3. Barbosa RHS. Mulheres, reprodução e Aids: as tramas da ideologia na assistência à saúde de gestantes HIV+ [tese]. Rio de Janeiro: Escola Nacional de Saúde Pública, Fundação Oswaldo Cruz; 200 I
4. Canavarro MC. Gravidez e maternidade - representações e tarefas de desenvolvimento. In: Canavarro MC, editor. Psicologia da gravidez e da maternidade. Coimbra: Quarteto Editora; 2001. p.17-49.

5. Carvalho CML, Galvão MTG. Enfrentamento da AIDS entre mulheres infectadas em Fortaleza-CE. Rev Esc Enferm USP 2008; 42(1): 90-7.

6. Solomon P, Wilkins S. Participation among women living with HIV: a rehabilitation perspective. AIDS Care 2008; 20(3): 292-6. 
7. Lobiondo-Wood G, Haber J. Pesquisa em Enfermagem: métodos, avaliação crítica e utilização. 4ªed. Rio de Janeiro: Guanabara Koogan; 200I.

8. Bardin L. Análise de conteúdo. 3aed. Lisboa: Persona; 2004.

9. Sanders LB. Women's voices: the lived experience of pregnancy and motherhood after diagnosis with HIV. J Assoc Nurses AIDS Care 2008; 19(1): 47-57.

10. Miranda KCL, Barroso MGT, Silva LMS, Silva MRF. Reflexões sobre o aconselhamento em HIV/AIDS em uma perspectiva freireana. Rev Bras Enferm 2008; 6I (6): 899-903.

11. Ministério da Saúde (BR). Secretaria de Políticas de Saúde. Aconselhamento pré e pós-teste anti-HIV em gestantes, parturientes e puérperas. Recomendações para a profilaxia da transmissão materno-infantil do HIV e terapia anti-retroviral. Brasília: Ministério da Saúde; 2001.

12. Vaz MJR, Barros SMO. Redução da transmissão vertical do HIV: desafio para a assistência de enfermagem. Rev Latino-am Enferm 2005; 8(2): 4l-6.

13. Pinto DS. Sexuality, vulnerability to HIV, and mental health: an ethnographic study of psychiatric institutions. Cad Saúde Pública 2007; 23(9): 2224-33.

14. Sousa AS, Kantorski LP, Bielemann VLM. A Aids no interior da família- percepção, silêncio e segredo na convivência social. Acta Scientiarum Health Sciences 2004; 26(1): 1-9.

15. Sanches RM. Escolhi a vida: desafios da Aids mental. São Paulo: Olho d'Água; 1997.

16. Machado MMT, Galvão MTG, Kerr-Pontes LRS, Cunha AJLA,
Leite AJM, Lindsay AC, et al. Acesso e utilização de fórmula infantil e alimentos entre crianças nascidas de mulheres com HIV/AIDS. Rev Eletr Enferm 2007; 9(3): 699-7II.

17. Barroso LMM, Galvão MTG. Avaliação de atendimento prestado por profissionais de saúde a puérperas com HIV/AIDS. Texto Contexto Enferm 2007; 16(3): 463-9.

18. Machado MMT, Braga MQC, Galvão MTG. Problemas com a mama puerperal revelados por mães soropositivas. Rev Enferm USP 2010; 44(1): 118-23.

19. Oliveira LA, Junior IF. Demandas reprodutivas e a assistência às pessoas vivendo com HIV/AIDS: limites e possibilidades no contexto dos serviços de saúde especializados. Cad Saúde Pública 2003; 19(Supl.2): 315-23.

20. Nóbrega AA, Oliveira FAS, Galvão MTG, Mota RS, Barbosa RM, Dourado MI, et al. Desire for a child among women living with HIV/AIDS in Northeast Brazil. AIDS Patient Care STDs, 2007; 2 I (4):26 I-7.

21. Oliveira F, Kerr L, Frota A, Nóbrega A, Bruno Z, Leitão T, et al. HIV positive women in Northeast Brazil: Tubal sterilization, medical recommendation and reproductive rights. AIDS Care, Nov 2007; 19(10): 1258-65.

22. Knauth D. Maternidade sob o signo da aids: um estudo sobre mulheres infectadas. In: Costa AO, organizador. Direitos tardios, saúde, sexualidade e reprodução na América Latina. São Paulo: PRODIR/FCC/EDITORA 34; 1997. p.39-64.

23. Barroso LMM, Carvalho CML, Galvão MTG, Vieira NFC, Barroso MGT. Aspectos éticos da interação enfermeiro-puérpera com HIV/Aids. I Bras Doenças Sexual Trans 2005; 17(3): 197-200. 